\title{
Sterilisation of People with Learning Disabilities: A Comparative Study of the UK and the US on the "Best Interests Test"
}

\author{
By Yvoni Komodromou*
}

\begin{abstract}
The sterilisation of people with learning disabilities is a subject of great importance as it is surrounded by ethical concerns. Ethical problems arise when viewing sterilisation of people with learning disabilities, regarding the violation of the basic human right to procreate along with the capacity to consent. Therefore, it is vital to implement certain safeguards to protect people with learning disabilities from falling victim to improper decision-making for their treatment. This paper comparatively analyses the ethical concept of the "best interests" of the patient in the jurisdictions of the UK and the US. The evolution of the decision-making process for sterilisation within these two countries is considered throughout its progression from a eugenics-based to a more ethics-based approach. Analysis of today's perception on this topic is presented in the paper, as the idea of determining whether or not sterilisation is in an individual's best interests can include paternalistic elements. This is a significant issue to examine because of the invasiveness of the procedure, the ethical concerns surrounding the topic as well as the essential removal of the human right to procreate. However, it is important to bear in mind the constant need to consider the best interests of the patient.
\end{abstract}

Keywords: Best Interests of the Patient, Comparative Analysis, Sterilisation, United Kingdom, United States

\section{Introduction}

The purpose of this paper is the consideration of sterilisation of people with learning disabilities, focusing on the best interests of the patient in a comparative study between the UK and the US. The treatment of people with learning disabilities encompasses many aspects of bioethics such as the capacity to consent, informed consent and the best interests of the patients (National Disability Authority 2009). However, this paper will specifically be examining the authority of the physician and courts to order the sterilisation of an individual with learning disabilities and the way in which they reach this decision. This is a highly contentious topic due to the nature and invasiveness of the procedure (Greenwood and Wilkinson 2013), while also keeping in mind the other side of the spectrum, regarding the procedure being in the best interests of the patient (The Guardian 2015).

The paper will consider how the "best interests test" compares and how it differs in the UK and US while also examining how the relevant authorities approach the issue of sterilisation regarding the best interests of the patient.

\footnotetext{
${ }^{*}$ LLM Graduate, University of Minnesota, USA.
} 


\section{Brief History on Sterilisation and Eugenics}

Eugenics is considered to be the improvement of our biological character by using methods to reach this aim (Wilkinson 2008). In the UK, sterilisation and in turn, eugenics, were deeply considered topics, in the beginning of the $19^{\text {th }}$ century through the "English Eugenics Society and the National Association for the Care of the Feeble-minded" (Roy et al. 2012). The "eugenists", during this time, claimed that social position was directly related to specific characteristics of an individual, such as mental ability (MacKenzie 1975). As these characteristics were oftentimes inherited, a rough equation was drawn between the idea of social standing and hereditary worth (MacKenzie 1975). This Society also proposed legislation in order to avert the idea of parenthood and reproduction in cases of individuals with learning disabilities. Nevertheless, this legislation never came to pass (Roy et al. 2012), as opposed to the US, where 32 States enacted their own sterilisation laws (Kaelber 2009). The idea of encouraging schemes relating to individuals with favourable traits to procreate and the discouragement of parenthood for those who were considered "unfit", however, had firmly established itself during this period (MacKenzie 1975).

In the United States, the case of Buck $v$ Bell (1927) jumpstarted a widespread phenomenon of sterilisation of mentally disabled people without their consent for eugenic purposes, claiming that this was to protect society as a whole (Roy et al. 2012). This case led to 65,000 sterilisations of people with developmental disabilities from the 1920s to the 1970s (Ko 2016). The harsh approach, enabled by Buck v Bell (1927) was backed up by the equally harsh words of Justice Oliver Wendell Holmes in the case, stating that "three generations of imbeciles are enough".

Despite the fact that sterilisation was a topic that was in the forefront of "eugenists" minds at the time, it is still of significance today as there are still cases of sterilisation of people with learning disabilities, as recent as 2015 (Mental Health Trust v DD 2015).

\section{United Kingdom}

\section{The "Best Interests Test"}

It is important to mention that, briefly, during the 1970s, sterilisation was a procedure governed by the distinction between therapeutic and non-therapeutic reasoning ( $\operatorname{Re} B$ 1987). However, based on two cases during that time, the courts found that the distinction was not a helpful test. In fact, the English courts were quite reluctant to state that non-therapeutic sterilisation was "never" justified (Tobin and Luke 2013). In the case of Re D (a minor) (1976), the mother of an 11-year old girl with Soto's Syndrome sought her sterilisation for reproductive and eugenic reasons. The Court held in this case, that there was overwhelming evidence that the girl's understanding of the issue would 
eventually improve, if given some time, and would eventually be able to make the decision herself ( $\operatorname{Re} \mathrm{D}$ (a minor) 1976). Going through with this nontherapeutic sterilisation without her consent, was deemed to be a violation of her basic right to reproduce ( $\operatorname{Re} \mathrm{D}$ (a minor) 1976).

The second case is that of $\operatorname{Re} B$ (1987), a few years later, regarding a 17year-old girl with the mental capacity of a six-year-old who, according to her doctors, would never truly understand the concepts of sex and pregnancy, even though she was exhibiting signs of sexual awareness. It was decided amongst her doctors that reproduction would be positively harmful to her $(\operatorname{Re} B$ 1987). Although the concern of depriving her of the human right to reproduce was brought up, the court made the point that this human right was only of value "if accompanied by the ability to make a choice" (Re B 1987). Therefore, the Court completely moved away from the test of therapeutic and non-therapeutic sterilisation and stated that this was not the correct consideration when dealing with this procedure (Norrie 1989). The paramount consideration, instead, according to the court, should be whether sterilisation is in the best interests of the patient and whether the procedure is necessary "for the welfare and benefit" of the patient $(\operatorname{Re} B 1987)$.

\section{Implementation of the "Best Interests Test"}

After determining that the best interests test would be the correct pathway when dealing with the question of whether or not to sterilise (Re B 1987), the case of $F v$ West Berks HA (1989) emphasised the point by stating that physicians should be able to operate on a person, unable to give their consent, when saving their life, to ensure improvement or to prevent physical or mental deterioration. Hence the reluctance of the UK courts to explicitly say that nontherapeutic sterilisations were in no way justifiable (Tobin and Luke 2013), as the last two points are not clearly therapeutic.

The Mental Capacity Act (MCA) of 2005 sets out a "best interests test" which provides guidelines when determining whether to operate on a patient. Firstly, the personal characteristics of the patient need to be considered including such things as their age, their personality or something that would "lead others to make unjustified assumptions about what might be in" their "best interests" (Mental Capacity Act 2005, section 4(1)). Also, the person's relevant circumstances (Mental Capacity Act 2005, section 4(2)) and the possibility that they will have the ability to consent to the treatment themselves in the future (Mental Capacity Act 2005, section 4(3)), need to be considered carefully. Finally, a very important element to the test would be the reasonable consideration of factors such as the wishes, beliefs and feelings of the individual before making a decision (Mental Capacity Act 2005, section 4(6)).

\section{Necessity and the "Best Interests Test"}

In conjunction with the "best interests test" found in section 4 of the MCA 2005, there is also a Practice Note which was designed in 1993. The purpose of 
this Practice Note was to set out a procedure for the decision-making process regarding the sterilisation of people with learning disabilities. The Practice Note consists of four elements that must be satisfied in order to authorise the sterilisation. Firstly, it is important to assess whether the patient is incapable of making his or her own decision and whether it is likely that this person will ever develop sufficient judgment to make this decision. Secondly, the possibility of the undesirable condition occurring, which in this case includes pregnancy and a definite possibility of engaging in sexual activity, should be considered. Thirdly, in the event that the individual will suffer a substantial trauma or psychological damage if these conditions occur, then sterilisation would be beneficial to the patient. Finally, there is a need to consider less invasive alternatives to the sterilisation while also assessing whether sterilisation would cause more damage than the trauma that would occur in the event of a pregnancy (Practice Note 1993).

These guidelines, along with the "best interest test" of the MCA 2005, aided in the decision made in a 2015 case (Mental Health Trust v DD 2015). This case was concerned with a 36-year-old woman who had Autistic Spectrum disorder with an IQ of 70. She had already had 6 children and wanted to have a seventh child. However, she had no contact with the children who had been taken away to permanent alternative care because of her developmental disability. Therefore, when she expressed her desire for another child, the local authority intervened, stating that she could not do so because of her inability to engage in the children's lives and provide them with a safe and nurturing environment. The court made it clear that this was not a case of eugenics but of avoiding the potential for "further pregnancy" which "would be a significantly life-threatening event for" the woman in question (Mental Health Trust v DD 2015). In fact, they went on to state that "the risk to" her, regarding a future pregnancy, "especially if concealed, is highly likely to lead to her death" (Mental Health Trust v DD 2015). Although it is clear from previous case-law (Re B 1987) that taking away a person's human right to procreate is a serious violation, "it may be justified in extreme circumstances" (Gallagher 2015).

\section{United States}

\section{The "Eugenics Approach" to Sterilisation}

It is important to note, that the "United States was the first country to undertake sterilisation for eugenic purposes" (Roy et al. 2012). As stated above, eugenics was considered to be the means of ensuring that society would be safe from the reproduction of individuals with "undesirable traits" and who were deemed inferior, including the poor, the mentally ill and the disabled (Ko 2016). This view was backed up by the Buck v Bell (1927) case already mentioned above. The opinion that prevailed during this time in history was that it would be better for the world "if instead of waiting to execute degenerate 
offspring for crime, or to let them starve for their imbecility, society" could prevent those who were "manifestly unfit from continuing their kind" (Buck v Bell 1927).

The United States case-law essentially was showcasing that the right to procreate was a protected right more in dicta rather than in reality (Binion 1988). In the case of Skinner v Oklahoma (1942), which was concerned with the compulsory sterilisation of criminals, it was decided that the prisoner should not undergo a sterilisation procedure. However, the decision was not reached with the contemplation of procreation being a fundamental right, but rather on the concern of discrimination between felons, regarding the type of crime they had committed. The fundamentality of the right to procreate was not in the forefront of the court's mind during the time these cases took place (Skinner v Oklahoma 1942).

\section{The "Best Interest Test" and Guidelines on Decision-Making}

By the first half of the $20^{\text {th }}$ century, 65,000 people had been sterilised (Roy et al. 2012) for eugenics-based purposes (Binion 1988). However, much like in the UK, the United States has tried to create certain standards and safeguards in order to prevent the idea of eugenics from resurfacing (Binion 1988). A prime example of guidelines would be the American College of Obstetrics and Gynaecologists 2007 recommendation.

This recommendation and subsequent recommendations have the primary intention of ensuring the respect of a woman's reproductive system. A physician needs to take care in the event of sterilisation procedures by providing pre-sterilisation counselling, stressing the permanence of the procedure (The American College of Obstetrics and Gynaecologists 2017). In the event that an individual's mental capacity is limited, then sterilisation has to be considered by the physician very carefully and he must consult with the individual's family, agents and other care givers (The American College of Obstetrics and Gynaecologists 2007). This requirement was included in order to ensure the formation of a plan that protects the individual. Specifically, the purpose of this recommendation is to protect a patient's best interests and autonomy (Roy et al. 2012).

Furthermore, the case of Re Grady (1981) has also provided important insight into the consideration of the decision-making process in relation to the sterilisation of individuals with a learning disability. The court set out a "test" of sorts in order to determine the best interests of an individual (Re Grady 1981), resembling the guidelines in the Practice Note (1993) of the UK on the subject of sterilisation. The court stated that in order to determine the best interests of a person with learning disabilities regarding the possibility of sterilisation, certain factors need to be considered, such as the possibility of a pregnancy along with the possibility of the individual experiencing trauma or psychological damage because of this pregnancy or giving birth. On the other hand, however, the court included in this factor, the need to consider the 
possibility of the occurrence of psychological damage in the event of the sterilisation operation (Re Grady 1981).

Furthermore, the inability of the individual to understand reproduction or contraception needs to be examined. Also, the feasibility of less "dramatic" means to allow for contraception is another factor that needs to be carefully considered. Finally, unlike the Practice Note in the UK, the court in Re Grady stated that the demonstration of the proponents of the sterilisation procedure need to showcase that their "primary concern is for the best interests" of the individual and that they are seeking this procedure in good faith. In other words, they should demonstrate that they are not seeking this procedure "for their own or the public's convenience" (Re Grady 1981).

\section{The Evolution of Sterilisation in both Countries}

As seen from the information disclosed above, both the UK and the US began the $20^{\text {th }}$ century with a eugenics-based approach to people with learning disabilities, with the purpose of preventing these individuals from procreating (Roy et al. 2012). Today, however, sterilisation is no longer performed for eugenic purposes in these countries. More specifically, the "best interests test" is the tool with which to determine the approval of a sterilisation procedure.

Furthermore, both jurisdictions have set up certain safeguards and tests, realising the need to ensure that sterilisation for eugenics-based purposes should not be repeated (McIntyre 2007). In the UK, the sterilisation of individuals with learning disabilities requires the authorisation of the court, which will act in what it deems are the best interests of the individual (Rowlands and Amy 2017). In the US, the same applies and as previously stated, the court needs to consider the recommendation of the parents or guardians, the feasibility of less intrusive means of contraception and the physical and emotional trauma caused by pregnancy (McIntyre 2007) as well as the sterilisation (Re Grady 1981).

\section{Ethical Concepts Regarding the best Interests of the Patient}

\section{Problems with the "Best Interests Test"}

It is all well and good to merely state that it is in the patient's best interests to be sterilised. But what does this mean? There are many ethical concerns that surround the "best interests" of the patient. For example, there may be disagreements over what is in fact in the best interests of the patient (Lo 2013). These disagreements can occur between the individual's relatives and physicians. Therefore, the best option in resolving the conflict is the communication regarding the benefits and burdens of an intervention of such magnitude (Lo 2013). 
It is important that all parties reach an agreement on how best to provide care to the individual. According to Lo, there must be some understanding of the patient's perspective on the matter (Lo 2013). Therefore, in the case of sterilisation, it would be prudent to understand whether or not a patient can comprehend the concepts of contraception, pregnancy and reproduction in general (McIntyre 2007). In the event that this patient does understand or will someday possibly understand what these concepts entail then the decision should be postponed until the complete comprehension by the patient occurs (Re D (a minor) 1976).

Another significant issue regarding the best interests of the patient is medical paternalism. Paternalism, in broad terms, "is an action performed with the intent of promoting another's good but occurring against the other's will or without the other's consent" (Drolet and White 2012). The biggest problem of medical paternalism is the fact that the physician may override the patient's wishes "because of their own psychological and emotional reaction" in each case (Drolet and White 2012). By allowing the physician's own emotions into the mix, there is a greater possibility for a return, however slight, of eugenics.

\section{Alternative Routes in Place of Sterilisation}

As mentioned earlier, it is also important to consider alternative routes to the best interests of individuals with learning disabilities regarding the need for medical intervention ( $\operatorname{Re}$ Grady 1981). Why were not other contraceptive measures that would not cause a permanent effect considered in the cases of $R e$ $D$ (a minor) and $R e \quad B$ mentioned above? Contraceptive pills and medroxyprogesterone injections could easily be used for "contraception and menstrual management" (Roy et al. 2012). These alternative methods to solving the problem are much less invasive and much less violating (McIntyre 2007). On the other hand, it is important to consider whether these alternatives could possibly create trauma of some sort (McIntyre 2007).

When considering the option of sterilisation, the physician and the patients' families must consider the fact that they are taking away a basic human right of reproduction and they must also consider the procedure itself. It is an operation, and with any operation there are risks (World Health Organization 2014). Therefore, disclosure of alternative approaches is necessary (Lo 2013).

\section{Conclusion}

After the strong eugenics movement in the UK (MacKenzie 1975) and the US (Kaelber 2009), both jurisdictions have put in place certain safeguards and procedures to ensure the protection of people with learning disabilities when determining the necessity of sterilisation. As can be seen by the above, these safeguards roughly consider the same factors, such as the possibility of 
psychological trauma when giving birth and being pregnant (Practice Note 1993). The United States, through case-law, have also included the factor of assessing whether the proponents of the sterilisation procedure are genuinely looking out for the best interests of the individual (Re Grady 1981).

Therefore, the predominant consideration in both countries is now the "best interests test". The test itself has been considered above, but there is also a need for a balance between helping the individual and not infringing upon their fundamental right to reproduce (World Health Organization 2014). Finally, alternative methods to sterilisation need to be implemented or at the very least considered first, before moving on to the more invasive procedure of sterilisation (Lo 2013).

\section{References}

Binion G (1988) Reproductive Freedom and the Constitution: The Limits on Choice. Berkeley Journal of Gender, Law \& Justice 4(1): 12-41.

Buck v Bell (1927) 274 U.S. 200.

Drolet BC, White CL (2012) Selective Paternalism. American Medical Association Journal of Ethics 14(7): 582-588.

$F v$ West Berks HA [1989] 2 All ER 545.

Gallagher J (2015) Mother of Six "Can be Sterilised" - Court Ruling. Retrieved from https://www.bbc.com/news/health-31128969. [Accessed 11 December 2018]

Greenwood NW, Wilkinson J (2013) Sexual and Reproductive Health Care for Women with Intellectual Disabilities: A Primary Care Perspective. International Journal of Family Medicine 2013: 642472. DOI: 10.1155/2013/642472.

Kaelber L (2009) Eugenics: Compulsory Sterilization in 50 American States. Retrieved from http://www.uvm.edu/ lkaelber/eugenics/ [Accessed 16 December 2017]

Ko L (2016) Unwanted Sterilization and Eugenics Programs in the United States. Retrieved form https://to.pbs.org/2VrH3qT. [Accessed 16 December 2017]

Lo B (2013) Resolving Ethical Dilemmas: A Guide for Clinicians, Pennsylvania: Lippincott Williams and Wilkins.

MacKenzie D (1975) Eugenics in Britain. Social Studies of Science 6(3/4): 499-532.

McIntyre M (2007) Buck v Bell and Beyond: A Revised Standard to Evaluate the Best Interests of the Mentally Disabled in the Sterilization Context. University of Illinois Law Review (4): 1303-1328.

Mental Capacity Act 2005.

Mental Health Trust $v$ DD [2015] EWCOP4.

National Disability Authority, (2009) Ethical Guidance for Research with People with Disabilities. Retrieved from: https://bit.ly/2Q7CKQm.

Norrie KMcK (1989) Sterilisation of the Mentally Disabled in English and Canadian Law. The International and Comparative Law Quarterly 38(2): 387-395.

Practice Note [1993] 3 All ER 222, 224.

The Guardian (2015) Judge Authorises Sterilization of mother-of-six with learning disabilities. Retrieved from https://bit.ly/2Q9iNIP. [Accessed 8 December 2017]

$\operatorname{Re} B$ [1987] 2 All ER 206.

$\operatorname{Re} D$ (a minor) [1976] 1 All ER 326.

Re Grady 85 N.J. 235, 426 A.2d. 467 (1981). 
Rowlands S, Amy J (2017) Sterilisation of those with intellectual disability: evolution from non-consensual interventions to strict safeguards. Journal of Intellectual Disabilities 2017: 17. DOI:10.1177/1744629517747162.

Roy A, Roy A, Roy M (2012) The human rights of women with intellectual disability. Journal of the Royal Society Medicine 105(9): 384-389.

Skinner v Oklahoma 316 U.S. 535 (1942).

The American College of Obstetricians and Gynecologists: Women's Health Care Physicians (2007) Sterilization of Women including those with Mental Disabilities. Obstetrics \& Gynecology 110(1): 217-220.

The American College of Obstetricians and Gynecologists: Women's Health Care Physicians (2017) Sterilization of Women: Ethical Issues and Considerations. Obstetrics \& Gynecology 129(4): 109-116.

Tobin J, Luke E (2013) The Involuntary, Non-Therapeutic Sterilisation of Women and Girls with an Intellectual Disability - Can it Ever be Justified?. Victoria University Law and Justice Journal 3(1): 27-46.

Wilkinson S (2008) "Eugenics Talk" and the Language of Bioethics. Journal of Medical Ethics 34(6): 467-471.

World Health Organization (2014) Eliminating forced, coercive and otherwise involuntary sterilization: an interagency statement, OHCHR, UN Women, UNAIDS, UNDP, UNFPA, UNICEF and WHO. World Health Organization. Retrieved from https://bit.ly/2EcJI1R. 
